\title{
Hyperglycaemia modifies the reaction of microvessels to insulin in rat skeletal muscle
}

\author{
C. Renaudin, E. Michoud, J. R. Rapin, M. Lagarde, N. Wiernsperger \\ Diabetic Microangiopathy Research Unit, Lipha-INSERM U 352, Villeurbanne, France
}

\begin{abstract}
Summary The role played by glucose and/or insulin in local vascular regulation of tissue glucose uptake is largely unknown. Thus, the aim of this study was to examine microvascular changes induced either by hyperinsulinaemia alone or in combination with hyperglycaemia. The effects of insulin or glucose on the diameter and periodic vasomotion of precapillary arterioles (diameter $<20 \mu \mathrm{m}$ ) were determined by using the spinotrapezius muscle preparation in fasted, anaesthetized rats. Ten minutes after s.c. insulin administration, the blood insulin level was greatly increased whereas plasma glucose remained unchanged. This was associated with a marked and durable vasodilation of terminal arterioles without significant changes in vasomotion. When similar plasma insulin levels were attained by glucose infusion, tissue glucose uptake was increased in spite of a partial constriction and increased vasomotion of precapillary arterioles. Importantly, local tissue blood flow was not reduced despite the diminution in microvascular
\end{abstract}

diameters. These results indicate that hyperinsulinaemia alone produces an increase in the diameter of terminal arterioles. This effect seems to be offset when the same level of hyperinsulinaemia is associated with hyperglycaemia (such as occurs postprandially), as illustrated by vasoconstriction of the muscle terminal arterioles. Our data suggest that the vasoconstriction of precapillary arterioles may be part of an active regulation for optimal glucose supply to the tissue in acute hyperglycaemic episodes. These data provide the first direct evidence that insulin and glucose can act as regulators of microflow in the skeletal muscle, as illustrated by changes in precapillary haemodynamics. [Diabetologia (1998) 41: 26--33]

Keywords Hyperglycaemia, hyperinsulinaemia, glucose uptake, blood flow, microcirculation, intravital microscopy, vasomotion, skeletal muscle, arteriole, rat.
Glucose homeostasis is partly due to the metabolic action of insulin, which exerts its antihyperglycaemic action mainly in liver, adipose tissue and skeletal muscle. In the basal state, skeletal muscle utilizes little glucose as a fuel for its own needs [1]. In contrast, during postprandial periods the disposal of glucose is partly insulin-mediated and occurs mainly in skeletal muscle [2], where it is largely stored as glycogen. At this time, skeletal muscle switches from a low glu-

Received: 30 May 1997 and in revised form: 3 September 1997

Corresponding author: C. Renaudin, Diabetic Microangiopathy Research Unit, Lipha-INSERM U 352, INSA-Lyon Bldg. 406, F-69621 Villeurbanne Cedex, France cose-consuming to a major carbohydrate-utilizing system. Glucose uptake is increased by the combined effects of the prevailing serum glucose concentration (mass action effect) and by endogenous insulin elevation which stimulates glucose extraction by recruiting and activating specific transporters.

In addition to the metabolic and nervous factors, blood flow might be another parameter regulating glycaemia. Under normal daily physiological conditions, plasma levels of glucose and insulin vary considerably, in particular during repeated postprandial periods. If these substances exert vasoactive effects, they may consequently play a prominent role in the optimal regulation of glucose homeostasis [3, 4]. Several studies have reported that, in addition to its met- 
abolic action, insulin also exerts haemodynamic effects in which the hormone appeared to induce vasodilation in skeletal muscle. By combining the euglycaemic clamp with the leg balance technique, studies demonstrated that insulin-induced vasodilation was preferentially directed towards skeletal muscle [5], was dose-dependent and, more importantly, occurred at insulin levels within the physiological range [6]. In healthy patients, various techniques for blood flow measurement such as thermodilution $[5,7]$ or plethysmography [8--11] have documented that, under euglycaemic conditions, hyperinsulinaemia can increase skeletal muscle blood flow.

The potential physiological importance of this phenomenon has been suggested in obese non-diabetic $[6,12]$, as well as in diabetic patients [13], in which a defect in insulin-induced vasodilation was shown to be associated with defective peripheral glucose uptake. However, this hypothesis has been challenged by a series of recent investigations [14--16].

Indeed all these studies concerned haemodynamic effects on large vessels and/or in whole organs. Moreover, studies investigating the vascular effects of high insulin levels have mainly been performed using the clamp procedure, in which normal dynamic changes are artificially eliminated due to the maintenance of constant hormone levels. However, macrovascular effects such as changes in forearm blood flow are only relevant if they occur in -- or at least if they are transmitted to -- the capillary bed which constitutes the ultimate site of exchange between blood and tissues [17]. That hyperinsulinaemia might also increase microflow has been suggested by non-invasive measurements in humans, in which it was postulated that the flow increase observed with insulin was mainly due to capillary recruitment [18--20].

Physiologically, however, plasma insulin levels increase subsequent to acute elevations of glycaemia. Currently no study has examined the direct effects of concomitant hyperinsulinaemia and hyperglycaemia on microvascular dimensions in situ, although they represent likely physiological stimuli of the vasculature. It therefore appears of upmost importance to investigate the vascular effects of insulin on the skeletal muscle microcirculation in both normo- and hyperglycaemia. The elucidation of possible haemodynamic effects of these compounds at the level of nutritive small vessels in normal animals was therefore the main objective of this in vivo study; knowledge of the microvascular reactivity to these physiological substances should constitute the basis for subsequent investigations in pathological situations such as insulin resistance and diabetes.

\section{Materials and methods}

Experimental protocols. Male Wistar rats (Iffa Credo, l'Arbresle, France) weighing 200--230 g were used for the experiments. The animals were kept under controlled conditions of light (07.00--19.00 hours), temperature $\left(22 \pm 1^{\circ} \mathrm{C}\right)$ and humidity $(50 \pm 10 \%)$.

Fasted rats were anaesthetized by intraperitoneal injection of $60 \mathrm{mg} / \mathrm{kg}$ pentobarbital sodium. The body temperature of animals was kept constant at $37 \pm 1{ }^{\circ} \mathrm{C}$ with a heating pad. The trachea was intubated with a polyethylene tube (PE-250, Guerbet Biomedical, Louvres, France) to facilitate spontaneous breathing. Polyethylene catheters (PE-50) were inserted into the jugular vein for drug injections and into the carotid artery for blood pressure measurement and blood sampling. Then, the ventral surface of the right spinotrapezius was surgically prepared for in vivo visualization. After completion of the surgical procedure, the animals were allowed to stabilize for $30 \mathrm{~min}$. Precapillary arterioles (smaller than $20 \mu \mathrm{m}$ ) were selected and the value of arteriolar diameter at this time was considered as basal diameter.

In a first series of experiments, animals were injected subcutaneously with insulin (Actrapid, Novo Nordisk Pharmaceutique S. A., Boulogne, France; $1 \mathrm{IU} / \mathrm{kg}$ and repeated injections of $0.25 \mathrm{mIU} / \mathrm{kg}$ every $15 \mathrm{~min} ; n=6)$. Rats injected with $\mathrm{NaCl}$ $0.9 \%(n=6)$ were used as controls. Insulinaemia and glycaemia were determined just before insulin administration and at time 12, 27 and $42 \mathrm{~min}$. Twelve minutes after insulin or isotonic saline injections, rats were injected with $\mathrm{U}_{-}{ }^{14} \mathrm{C}$-2-deoxy-glucose (2-DG; $0.1 \mathrm{mCi} \cdot \mathrm{kg}^{-1}$; i.v.) to determine glucose uptake during the 45 min of the experiment.

In a second series of experiments, animals were infused intravenously with $1.3 \mathrm{ml}$ of glucose during $1 \mathrm{~min}(1.5 \mathrm{~g} / \mathrm{kg}$; $n=7)$. Rats infused with $0.9 \% \mathrm{NaCl}$ i.v. $(n=6)$ were used as controls. Insulinaemia and glycaemia were determined just before glucose administration and at time 10, 25 and $40 \mathrm{~min}$. Ten minutes after glucose or $0.9 \% \mathrm{NaCl}$ infusions, rats were injected with U- ${ }^{14} \mathrm{C}-2$-deoxy-glucose (2-DG; $0.1 \mathrm{mCi} \cdot \mathrm{kg}^{-1}$; i.v.) to determine glucose uptake during the 45 min of the experiment. Video recording was performed at 15, 30 and 45 min after injection in order to measure, off-line, the arteriolar diameters and vasomotion. At the end of the last recording period, the microvascular blood flow in the spinotrapezius muscle was measured by injected ${ }^{125}$ I-isopropyl-iodo-amphetamine (IAMP; $0.3 \mathrm{mCi} \cdot \mathrm{kg}^{-1} ;$ i.v.) and the rats were killed $3 \mathrm{~min}$ after its administration.

In a separate group, plasma osmolality was measured at time $0,5,15,30$ and $45 \mathrm{~min}$ after glucose infusion $(1.5 \mathrm{~g} / \mathrm{kg})$.

Preparation of the spinotrapezius muscle. The right spinotrapezius was surgically prepared according to the method described by Gray [21]. Briefly, a longitudinal slit was performed in the skin along the spine from the cervical to the midlumbar region. The connective tissue which covers the muscle was carefully removed. A slit was made with iridectomy scissors at the lateral border of the spinotrapezius and its ventral surface was exposed; four sutures were tied to the border of the muscle at $1 \mathrm{~cm}$ intervals to keep the spinotrapezius exteriorized, in situ.

During the preparation and experimental observations, the skeletal tissue was continuously superfused with a bicarbonate/ HEPES-buffered saline solution containing (in mmol/l) 110 $\mathrm{NaCl}, 4.7 \mathrm{KCl}, 2 \mathrm{CaCl}_{2}, 1.2 \mathrm{MgSO}_{4}, 18 \mathrm{NaHCO}_{3}, 15.39 \mathrm{HEPES}$ and 14.61 HEPES Na${ }^{+}$-salt. The temperature of the solution was kept at $36^{\circ} \mathrm{C}$ and the $\mathrm{pH}$ was set at 7.4 by bubbling the solution continuously with $5 \% \mathrm{CO}_{2}$ in $95 \% \mathrm{~N}_{2}$. Superfusion flow rate was maintained at $4--5 \mathrm{ml} / \mathrm{min}$. 
Intravital microscopy. To visualize the microcirculation, the preparation was placed under an intravital microscope (Axioplan, Carl Zeiss, Oberkochen, Germany), and the spinotrapezius muscle was observed by transillumination. Images of the vessels were examined by a close-circuit video system including a black and white camera (4912--5000, Cohu, San Diego, Calif., USA), a video timer (VTG-33; For. A, Tokyo, Japan), an S-VHS video cassette recorder (BR-S605E; JVC, Tokyo, Japan) and a black and white monitor. This equipment, with a $\times 10$ long distance Epiplar objective (Carl Zeiss, Oberkochen, Germany), allowed the observation of microcirculatory fields of $1 \times 0.77 \mathrm{~mm}$. The magnification range was calculated using a stage micrometer. A Shott BG 12 blue band pass filter helped to increase the image contrast.

Microcirculatory fields were selected for observation based on image clarity and branching order. Each field was recorded for $2 \mathrm{~min}$. The video signal was digitized through an acquisition board Raptor Bitflow (Imasys, Suresnes, France) placed in a PC 486 microcomputer.

Arteriolar diameters were determined by measurements of the red blood column diameters, the median value of at least five consecutive diameter measurements being considered as the real diameter. This was realized by a playback analysis of the video record using a self-developed image processing system. The image was coded as 768 by 572 pixels, with 256 grey levels. The isotropic orientation of the vessel was used to increase the signal/noise ratio, by integration of the segments perpendicular to the user's defined segment. The diameters were computed at $50 \%$ of the grey level amplitude of the integrated signal.

The percentage of the selected arterioles presenting vasomotion, defined as rhythmic variations of the vessel diameter ( 1 to 8 cycles per min), was also determined in each experimental group. To do this, the film of the experiment was played back at a speed of \pm 4 times normal to perceive more clearly any variation of the vessel diameter.

Blood pressure measurements. The arterial blood pressure signal, transmitted to a blood pressure analyser (Harvard Apparatus 60--3003, South Natick, Mass., USA), was digitized at 100 samples/s. Each second, mean blood pressure and heart rate were computed, displayed and stored using a dedicated software developed under Labview for Windows (National Instrument, Austin, Texas, USA). All animals with a mean arterial pressure less than $90 \mathrm{mmHg}$ were excluded. The blood pressure values at time $0,15,30$ and $45 \mathrm{~min}$ are the average values measured during $5 \mathrm{~min}$, i. e. during each period of video recording.

Microvascular blood flow. ${ }^{125}$ I-labeled isopropyl-amphetamine (C.E. A., Saclay, France) was used as a tracer for microvascular perfusion. This compound is trapped by the endothelium on its first passage through the vessels and permits measurements similar to those using the smallest microspheres [22]. The tracer was injected intravenously $3 \mathrm{~min}$ before the end of the experiment and muscle samples were counted in a ${ }^{125} \mathrm{I}$ calibrated gamma-counter.

Local skeletal muscle glucose uptake. Glucose uptake was measured according to the technique described by Sokoloff et al. [22], using ${ }^{14} \mathrm{C}-2-\mathrm{DG}$ (NEN Life Science Products, Les Ulis, France) as a circulating tracer. Muscle glucose consumption was calculated after determination of the plasma elimination kinetics of 2-DG and glycaemia. The radiolabelled tracer was injected i.v. and blood samples collected at 15, 30 and $45 \mathrm{~min}$. At the end of this period, skeletal muscle was removed and solubilized in Soluene-350. Radioactivity was measured in a calibrated beta-counter after addition of $10 \mathrm{ml}$ Hionic-Fluor as liquid scintillation.
Analytical methods. Arterial blood samples $(400 \mu \mathrm{l})$ were collected in Eppendorf tubes for glycaemia, insulinaemia and osmolality determinations. Plasma glucose concentrations were measured by the glucose oxidase method. Serum insulin levels were determined by an insulin CT radioimmunoassay kit (CIS Bio International, ORIS Group, Gif/Yvette, France). Plasma osmolality was measured using a micro-osmometer model $3 \mathrm{MO}+$ (Advanced Instruments Inc., Worwood, Mass., USA).

Statistical analysis. Results are expressed as mean \pm SEM. Between-group comparisons of metabolic parameters were performed using the Mann Whitney test. The data for blood pressure and arteriolar diameters were analysed using two-way analysis of variance (ANOVA) to identify time and drug effects. When a significant value was demonstrated, one-way ANOVA was performed, followed by the Scheffe-test, to analyse the time effect in each experimental group and drug effect for each series of experiment. Between groups, comparisons of the percentage of arteriolar vasomotion were made using the chi-square test. $p$ less than 0.05 was considered statistically significant.

\section{Results}

\section{Effects of insulin injection}

1. Metabolic parameters. Glycaemia and insulinaemia were not modified by isotonic saline. Twelve minutes after the first subcutaneous insulin injection, plasma insulin was increased $(915 \pm 74$ vs $129 \pm 20 \mathrm{pmol} / \mathrm{l})$, without modification of blood glucose. Insulin injected animals maintained an elevated insulinaemia throughout the experiment and showed a moderate but significant decrease in glycaemia which developed progressively (Table 1).

\section{Blood pressure, arteriolar diameter and vasomo-} tion. Blood pressure, heart rate, arteriolar diameters and percentage of vasomotion remained unmodified in the saline group. Insulin did not modify heart rate but induced a moderate decrease in blood pressure; the effect being significant at time 30 and 45 min (Table 1). Arteriolar diameters in the spinotrapezius muscle were significantly increased by insulin. This vasodilation was already present at time $15 \mathrm{~min}$, and persisted until the end of the experiment (Fig.1). Percentage of arteriolar vasomotion was unaffected by insulin or isotonic saline (data not shown).

3. Glucose uptake. As expected, insulin injection induced a significant increase in muscle glucose uptake $\left(2.81 \pm 0.5\right.$ vs $1.63 \pm 0.21 \mu \mathrm{mol} \cdot \mathrm{min}^{-1} \cdot 100 \mathrm{~g} \mathrm{muscle}{ }^{--}$ ${ }^{1}$, in control group).

\section{Effects of intravenous glucose infusion}

1. Metabolic parameters. No modification of glycaemia or insulinaemia was observed in the control group. As expected, 10 min after intravenous infusion 
Table 1. Evolution of glycaemia, insulinaemia, mean arterial blood pressure and heart rate, following injections of insulin or isotonic saline in 7-week-old fasted rats

\begin{tabular}{llll}
\hline & $\begin{array}{l}\text { Time after the } \\
\text { first injection } \\
(\mathrm{min})\end{array}$ & $\begin{array}{l}\text { Isotonic saline } \\
(n=6)\end{array}$ & $\begin{array}{l}\text { Insulin } \\
(n=6)\end{array}$ \\
\hline $\begin{array}{lll}\text { Blood glucose } \\
\text { (mmol/l) }\end{array}$ & $\mathrm{t}=0$ & $5.2 \pm 0.4$ & $5.2 \pm 0.3$ \\
& $\mathrm{t}=12$ & $5.5 \pm 0.5$ & $4.8 \pm 0.2$ \\
& $\mathrm{t}=27$ & $5.3 \pm 0.3$ & $3.9 \pm 0.2^{\mathrm{a}, \mathrm{b}}$ \\
Plasma insulin & $\mathrm{t}=42$ & $5.1 \pm 0.3$ & $3.3 \pm 0.3^{\mathrm{a}, \mathrm{b}}$ \\
(pmol/l) & $\mathrm{t}=0$ & $132 \pm 27$ & $129 \pm 20$ \\
& $\mathrm{t}=12$ & $116 \pm 21$ & $915 \pm 74^{\mathrm{a}, \mathrm{b}}$ \\
& $\mathrm{t}=27$ & $121 \pm 19$ & $903 \pm 52^{\mathrm{a}, \mathrm{b}}$ \\
Mean arterial & $\mathrm{t}=42$ & $139 \pm 28$ & $873 \pm 49^{\mathrm{a}, \mathrm{b}}$ \\
blood pressure & $\mathrm{t}=0$ & $118 \pm 5$ & $129 \pm 5$ \\
(mmHg) & $\mathrm{t}=15$ & $113 \pm 5$ & $123 \pm 5$ \\
& $\mathrm{t}=30$ & $110 \pm 4$ & $114 \pm 8^{\mathrm{a}}$ \\
Heart rate & $\mathrm{t}=45$ & $107 \pm 4$ & $112 \pm 3^{\mathrm{a}}$ \\
(beats/min) & $\mathrm{t}=0$ & $432 \pm 10$ & $432 \pm 10$ \\
& $\mathrm{t}=15$ & $404 \pm 11$ & $432 \pm 13$ \\
& $\mathrm{t}=30$ & $398 \pm 11$ & $423 \pm 11$ \\
& $\mathrm{t}=45$ & $408 \pm 11$ & $438 \pm 9$ \\
\hline
\end{tabular}

Data are means \pm SEM

Insulin was administered subcutaneously at a dose of $1 \mathrm{UI} / \mathrm{kg}$ (time 0 ) and $0.25 \mathrm{IU} / \mathrm{kg}$ (time 15 and $30 \mathrm{~min}$ )

${ }^{\mathrm{a}} p<0.05$ vs time $0,{ }^{\mathrm{b}} p<0.05$ vs controls

Table 2. Evolution of glycaemia, insulinaemia, mean arterial blood pressure and heart rate following intravenous infusions of glucose $1.5 \mathrm{~g} / \mathrm{kg}$ and isotonic saline in 7-week-old fasted anaesthetized rats

\begin{tabular}{lllc}
\hline & $\begin{array}{l}\text { Time after } \\
\text { infusion }(\mathrm{min})\end{array}$ & $\begin{array}{l}\text { Isotonic saline } \\
(n=6)\end{array}$ & $\begin{array}{l}\text { Glucose } \\
(n=7)\end{array}$ \\
\hline $\begin{array}{lll}\text { Blood glucose } \\
\text { (mmol/l) }\end{array}$ & $\mathrm{t}=0$ & $5.8 \pm 0.2$ & $5.7 \pm 0.4$ \\
& $\mathrm{t}=10$ & $5.8 \pm 0.2$ & $16.9 \pm 0.5^{\mathrm{a}, \mathrm{b}}$ \\
& $\mathrm{t}=27$ & $6.1 \pm 0.2$ & $8.1 \pm 0.3^{\mathrm{a}, \mathrm{b}}$ \\
Plasma insulin & $\mathrm{t}=40$ & $6.0 \pm 0.2$ & $6.9 \pm 0.3^{\mathrm{a}}$ \\
(pmol/l) & $\mathrm{t}=0$ & $119 \pm 16$ & $121 \pm 11$ \\
& $\mathrm{t}=10$ & $119 \pm 8$ & $816 \pm 58^{\mathrm{a}, \mathrm{b}}$ \\
& $\mathrm{t}=27$ & -- & - \\
Mean arterial & $\mathrm{t}=40$ & $126 \pm 10$ & $150 \pm 34$ \\
blood pressure & $\mathrm{t}=0$ & $118 \pm 7$ & $119 \pm 4$ \\
(mmHg) & $\mathrm{t}=15$ & $119 \pm 7$ & $115 \pm 5$ \\
& $\mathrm{t}=30$ & $117 \pm 7$ & $115 \pm 4$ \\
Heart rate & $\mathrm{t}=45$ & $118 \pm 7$ & $116 \pm 4$ \\
(beats/min) & $\mathrm{t}=0$ & $398 \pm 11$ & $385 \pm 12$ \\
& $\mathrm{t}=15$ & $397 \pm 14$ & $391 \pm 10$ \\
& $\mathrm{t}=30$ & $418 \pm 15$ & $392 \pm 8$ \\
& $\mathrm{t}=45$ & $399 \pm 10$ & $400 \pm 10$ \\
\hline
\end{tabular}

Data are means \pm SEM

${ }^{\mathrm{a}} p<0.05$ vs time $0,{ }^{\mathrm{b}} p<0.05$ vs controls

of glucose, blood glucose and insulin were markedly increased. At the end of the experiment, insulinaemia had returned to baseline values whereas blood glucose remained only slightly but significantly increased (Table 2).

2. Blood pressure, arteriolar diameter and vasomotion. As shown in Table 2 and in Figures 2 and 3,

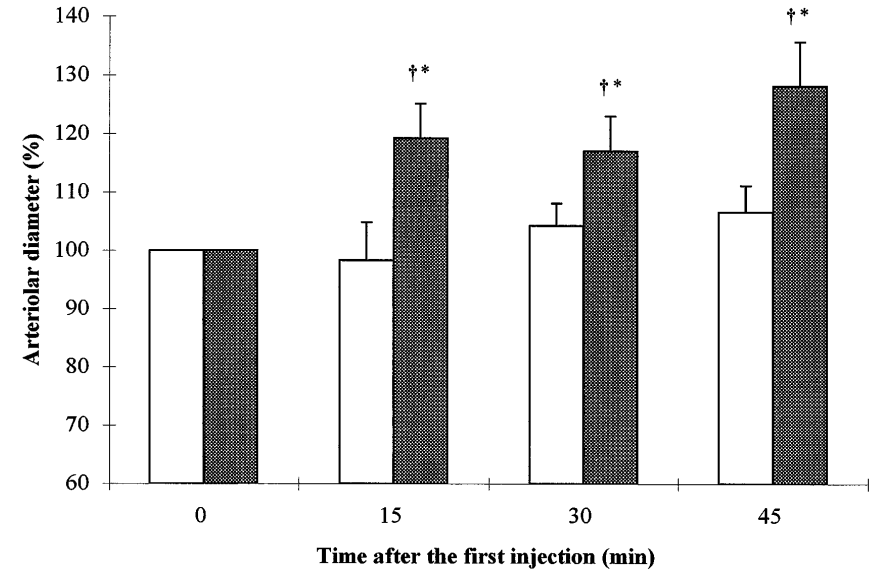

Fig. 1. Effects of insulin $(\square)$ or isotonic saline $(\square)$ on the skeletal muscle precapillary arteriolar diameters in 7-week-old fasted rats. Insulin was administered subcutaneously at a dose of $1 \mathrm{IU} / \mathrm{kg}$ (time 0 ) and $0.25 \mathrm{IU} / \mathrm{kg}$ (time 15 and $30 \mathrm{~min}$ ). $* p<0.05$ vs controls, $\uparrow p<0.05$ vs time 0

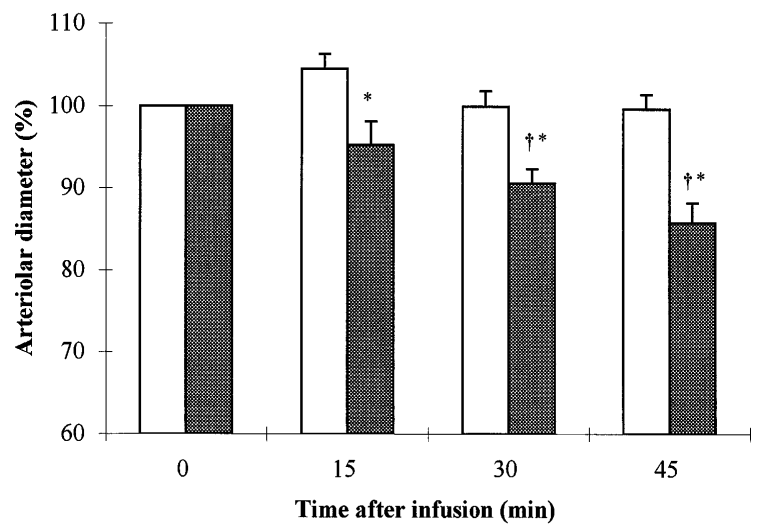

Fig. 2. Effects of intravenous infusion of glucose $(1.5 \mathrm{~g} / \mathrm{kg} ; 0)$ or isotonic saline $(\square)$ on skeletal muscle precapillary arteriolar diameters in 7 -week-old fasted rats. $* p<0.05$ vs controls, $\uparrow p<0.05$ vs time 0

blood pressure, vessel diameters and percentage of vasomotion remained unchanged after isotonic saline infusion at any time of the experiment. In contrast, 15 min after glucose administration, the animals exhibited a significant decrease in the arteriolar diameters. This vasoconstriction persisted until the end of the experiment and was associated with a progressive increase in the percentage of the vasomotion, the effect being significant at time 30 and $45 \mathrm{~min}$. However, no change in the mean blood pressure was observed in glucose-injected animals.

3. Blood flow and glucose uptake. Measurements of microvascular blood flow performed at the end of the experiment showed comparable values in glucose- and saline-injected animals $(9.2 \pm 2.5$ vs $7.1 \pm 1.7 \mathrm{ml} \cdot \mathrm{min}^{-1} \cdot 100 \mathrm{~g} \mathrm{muscle}{ }^{-1}$, in control group). Glucose infusion induced a significant in- 


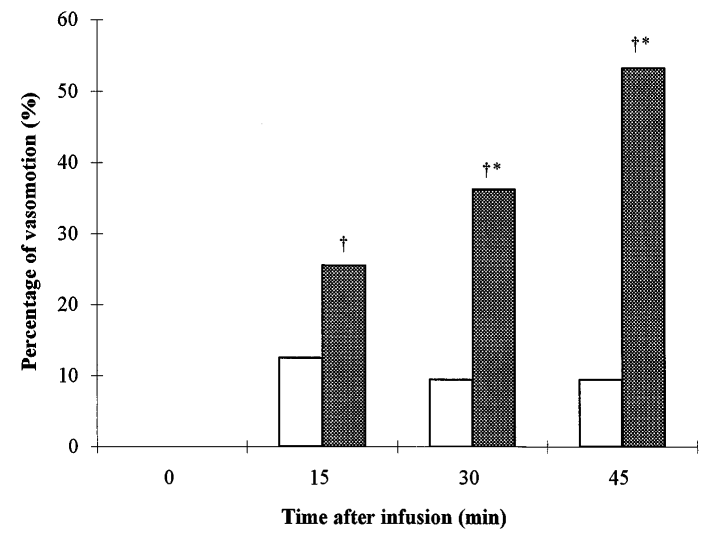

Fig.3. Effects of intravenous infusion of glucose $(1.5 \mathrm{~g} / \mathrm{kg}$; $)$ or isotonic saline $(\square)$ on percentage of precapillary arteriolar vasomotion in 7 -week-old fasted rats. ${ }^{*} p<0.05$ vs controls, $\dagger p<0.05$ vs time 0

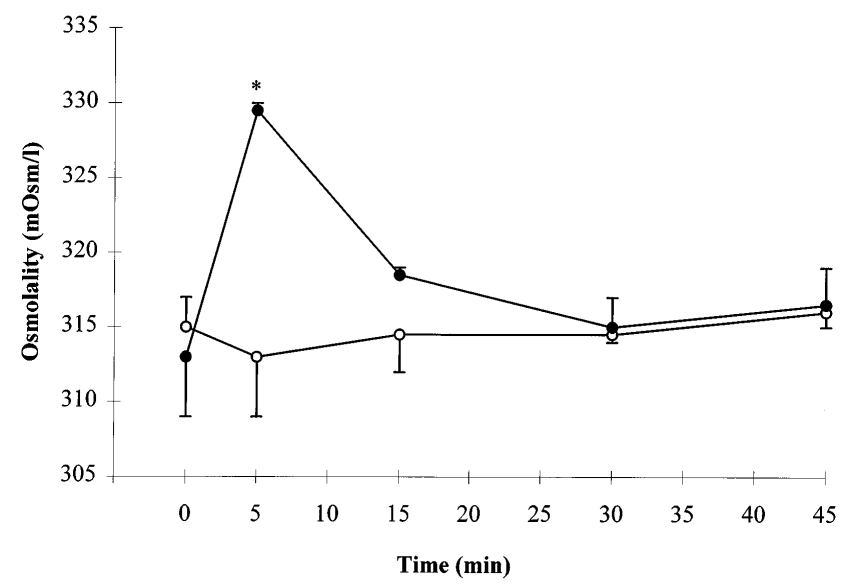

Fig.4. Evolution of osmolality after intravenous infusion of glucose $(1.5 \mathrm{~g} / \mathrm{kg} ; \bigcirc)$ or isotonic saline $(\bigcirc)$ in 7-week-old fasted rats. $* p<0.05$ vs controls

crease in muscle glucose uptake $(3.9 \pm 1.2$ vs $2.2 \pm 0.5 \mu \mathrm{mol} \cdot \mathrm{min}^{-1} \cdot 100 \mathrm{~g}$ muscle ${ }^{-1}$, in control group).

4. Osmolality. Lastly, as indicated in Figure 4, glucose administration induced an initial rise in osmolality which, however, returned to normal at 15 min postinfusion and was not different from controls for the duration of the experiment.

\section{Discussion}

Skeletal muscle is a main target tissue for insulin action to promote glucose uptake. During the postprandial period, this action is strongly stimulated to build up glycogen stores. Blood flow has been suggested to participate in this process [24] but the role of increased flow per se in determining peripheral glucose uptake remains controversial [14--16, 25]. Moreover, most clinical techniques for measuring blood flow are limited to an estimation of the global organ flow because of their non-invasive nature. However, nutrient delivery depends on the blood flowing through the terminal feeding vessels which branch into capillary units. Differences in the techniques used to measure blood flow can induce misinterpretations since the determining factor is where blood is ultimately flowing through $[17,26]$. It is therefore important to investigate whether insulin and glucose influence the dynamics of small blood vessels in vivo, since those substances fluctuate to large extent several times daily.

We first determined whether the vasodilation in large vessels with insulin observed in many studies was also manifested at the microcirculatory level. Indeed, we found that, in the physiological range, the hormone induced a clear increase in the diameter of the precapillary arterioles. Our data are in good agreement with clinical observations [5, 7--11] as well as with studies on isolated small vessels in vitro [27] or in the cremaster muscle in vivo [28]. This effect was seen both during normoglycaemia and during the moderate hypoglycaemia which followed insulin administration.

Most investigations on the haemodynamic effects of insulin have been performed by using the clamp procedure. However, the latter presents at least two drawbacks in relation with this type of study: a) hyperinsulinaemia, in addition to likely exceeding physiological levels, is usually induced in the presence of euglycaemia and b) the physiological dynamics of glycaemia and insulinaemia are lost. This context does not correspond to the daily profile of these compounds in blood and therefore we were interested in looking at the haemodynamic effects of acute hyperglycaemia. Intravenous infusion was selected as the method of glucose administration in order to ensure homogeneity in plasma glucose kinetics. The protocol was adjusted so that the resulting plasma insulin levels were similar to those attained with insulin alone. Our data clearly show that in this situation, where high insulin concentrations, coexist with high glucose (as occurs during postprandial periods), the diameter of terminal arterioles decreases in the absence of any significant modification in mean arterial blood pressure. Our data demonstrate that, at similar plasma insulin concentrations, the vasodilation observed with insulin alone does not occur when concomitant hyperglycaemia exists. The suggestion that acute hyperglycaemia can induce vasoconstriction is corroborated by several observations: in vitro, glucose favours vasoconstriction [29,30] and, in vivo, glucose impairs the endothelium dependent vasodilation in rat intestinal or cerebral arterioles $[31,32]$ as well as in human forearm [33].

Although clarification of these hypotheses was beyond the scope of our present investigations, several 
explanations can be proposed. First, the level of glycaemia achieved shortly after infusion induces an early increase in plasma osmolality, but arteriolar constriction was still observed at times when osmolality had returned to normal long before. The haemodynamic effects of osmolality are largely unknown but, if anything, are rather characterized by vasodilation $[34,35]$. Second, a direct constrictive effect of glucose could also result from enhanced production of some prostanoïds [36, 37], endothelin [38] or a stimulation of protein kinase C [39--41]. Third, since vessel caliber is also largely influenced by metabolites in the surrounding tissue, products of local glucose utilization in the muscle may have induced local vasoconstriction. However, we and others did not observe any change in small vessel diameter when the exteriorized muscle was superfused with high glucose, thereby making this hypothesis unlikely [Michoud E., unpublished results; 42]. Finally, terminal arteriolar constriction may also be driven by nervous inputs since both insulin and glucose are known to stimulate different components of the sympathetic nervous system [43, 44]. Future studies will be implemented to identify the precise mechanisms.

Our data also show that increased glucose consumption was achieved in spite of a partial constriction of terminal supplying arterioles in the anaesthetized preparation of the skeletal muscle. In contrast to the exercising muscle in which flow increases to adapt to the metabolic needs of the tissue, there is less evidence for a coupling between both parameters in the resting state. This disagrees with the initial proposal by Baron et al. [24] but is in line with several recent reports suggesting that muscle flow and glucose uptake are not necessarily linked [14--16, 25]. On the other hand, it is worth noting that, at $45 \mathrm{~min}$ post-infusion, local blood flow in our preparation was not reduced despite partial reduction in arteriolar diameter. This situation, which might appear paradoxical at first can be explained by the concomitant increase in arteriolar vasomotion which is seen in a large number of arteriolar branches. This phenomenon is well documented in the microcirculation research area, and appears as a cyclic contraction/relaxation observable in most vascular beds at the level of the small feeding vessels [45]. Vasomotion is a regulatory process that ensures an optimal time-related distribution of blood through vicinal capillary units, so that more microvessels are perfused per unit time with the same amount of blood $[46,47]$ and is considered to be linked to an increase in microvascular tone [48--50]. Our results therefore suggest that, whereas flow must be decreased in individual capillary units supplied by arterioles with reduced caliber, global tissue perfusion is not reduced but maintained at a constant level. This is what is expected from the initiation of vasomotion as a physiological regulatory phenomenon optimizing the delivery of blood in an "economic" " fashion. Thus, when investigating blood flow at the terminal level of the vascular bed, we have no evidence to support an increase in flow in the spinotrapezius muscle under conditions of physiological, i.e. glucose mediated, hyperinsulinaemia. This finding agrees with a lack of forearm blood flow modification after a mixed meal in humans [51]. One might hypothesize that the reduction in arteriolar diameter prevents capillaries from increased pressure and/or redistributes blood through the microvascular bed in a most efficient way, in order to supply more muscle fibers for glucose storage.

In conclusion, our data provide the first demonstration that, under conditions of dynamic changes, characterized by combined hyperinsulinaemia and hyperglycaemia such as occurs after meals, major microvascular modifications can be seen. In particular, hyperinsulinaemia is no longer vasodilating in such conditions either because this property is lost or is blunted by a marked vasoconstrictive effect of glucose. However, local blood flow was not reduced but in contrast was kept constant, probably reflecting a redistribution of blood in an optimized fashion. Arteriolar constriction is known to be a key mechanism in microcirculatory physiology as exemplified by the myogenic reflex [52]. Impaired arteriolar vasoconstriction has been demonstrated in various studies in diabetic animals and patients, when microvessels were challenged by various tests [53--55]. This defect has led to the 'haemodynamic hypothesis' of diabetic microvascular complications [56]. A disorder of peripheral vasomotion has also been found in diabetic microangiopathy [57--59]. It will therefore be interesting to extend these studies towards states of experimental insulin resistance and diabetes, in order to determine whether microvascular defects are involved in the reduced muscle glucose utilization under such circumstances.

Acknowledgements. We thank Dr. J. Lecerf for help in radioactivity analysis and Dr. A. Bataillard for valuable advice. We also thank Mr. M. Scarna for excellent technical assistance.

\section{References}

1. Andres R, Cader G, Zierler K (1956) The quantitatively minor role of carbohydrate in oxidative metabolism by skeletal muscle in intact man in the basal state. Measurements of oxygen and glucose uptake and carbon dioxide and lactate production in the forearm. J Clin Invest 35: 671--682

2. Ferrannini E, DeFronzo R (1997) Insulin action in vivo: glucose metabolism. In: Alberti KGMM, Zimmet P, De Fronzo RA (eds) International textbook of diabetes mellitus, Vol 1. Wiley \& Sons, Chichester, pp 505--530

3. Baron AD, Steinberg HO, Chaker H, Leaming R, Johnson A, Brechtel G (1995) Insulin-mediated skeletal muscle vasodilation contributes to both insulin sensitivity and responsiveness in lean humans. J Clin Invest 96: 786--792 
4. Baron AD (1996) The coupling of glucose metabolism and perfusion in human skeletal muscle. Diabetes 5 [Suppl 1]:S105--S109

5. Baron AD, Brechtel G (1993) Insulin differentially regulates systemic and skeletal muscle vascular resistance. Am J Physiol 265:E61--E67

6. Laakso M, Edelman SV, Brechtel G, Baron AD (1990) Decreased effect of insulin to stimulate skeletal muscle blood flow in obese man: a novel mechanism for insulin resistance. J Clin Invest 85: 1844--1852

7. Edelman SV, Laakso M, Wallace P, Brechtel G, Olefsky JM, Baron AD (1990) Kinetics of insulin-mediated and non-insulin-mediated glucose uptake in humans. Diabetes 39: $955--964$

8. Anderson EA, Hoffman RP, Balon TW, Sinkey CA, Mark AL (1991) Hyperinsulinemia produces both sympathetic neural activation and vasodilation in normal humans. $\mathrm{J}$ Clin Invest 87: 2246--2252

9. Vollenweider P, Tappy L, Randin D et al. (1993) Differential effects of hyperinsulinemia and carbohydrate metabolism on sympathetic nerve activity and muscle blood flow in humans. J Clin Invest 92: 147--154

10. Vollenweider P, Tappy L, Owlya R, Je<'quier E, Nicod P, Scherrer U (1995) Insulin-induced sympathetic activation and vasodilation in skeletal muscle. Diabetes 44: 641--645

11. Scherrer U, Randin D, Vollenweider P, Vollenweider L, Nicod P (1994) Nitric oxide release accounts for insulin's vascular effects in humans. J Clin Invest 94: 2511--2515

12. Vollenweider P, Randin D, Tappy L, Je $<$ 'quier E, Nicod P, Scherrer U (1994) Impaired insulin-induced sympathetic neural activation and vasodilation in skeletal muscle in obese humans. J Clin Invest 93: 2365--2371

13. Laakso M, Edelman SV, Brechtel G, Baron AD (1992) Impaired insulin mediated skeletal muscle blood flow in patients with NIDDM. Diabetes 41: 1076--1083

14. Mijares AH, Jensen MD (1995) Contribution of blood flow to leg glucose uptake during a mixed meal. Diabetes 44: 1165--1169

15. Raitakari M, Nuutila P, Ruotsalainen U et al. (1996) Evidence for dissociation of insulin stimulation of blood flow and glucose uptake in human skeletal muscle. Diabetes 45: 1471--1477

16. Jamerson KA, Nesbitt SD, Amerena JV, Grant E, Julius S (1996) Angiotensin mediates forearm glucose uptake by hemodynamic rather than direct effects. Hypertension 27: 854--858

17. Wiernsperger N (1994) Vascular defects in the aetiology of peripheral insulin resistance in diabetes. A critical review of hypotheses and facts. Diabetes Metab Rev 10: 287--307

18. Flynn MD, Boolell M, Tooke JE, Watkins PJ (1992) The effect of insulin infusion on capillary blood flow in the diabetic neuropathic foot. Diabet Med 9: 630--634

19. Baron AD (1994) Hemodynamic actions of insulin. Am J Physiol 267:E187--E202

20. Rattigan S, Barrett EJ, Clark MG (1997) Evidence of capillary recruitment by insulin but not epinephrine in rat skeletal muscle in vivo Diabetes 46 [Suppl 1]:84A (Abstract)

21. Gray SD (1973) Rat spinotrapezius muscle preparation for microscopic observation of the terminal vascular bed. Microvasc Res 5: 395--400

22. Rapin JR, Le Poncin-Lafitte M, Duterte D, Rips R, Morier E, Lassen NA (1984) Iodoamphetamine as a new tracer for local cerebral blood flow in the rat: comparison with isopropyliodoamphetamine. J Cerebr Blood F Met 4: 270--274

23. Sokoloff L, Reivich M, Kennedy C et al. (1977) The $\left[{ }^{14} \mathrm{C}\right]$ deoxyglucose method for the measurement of local cere- bral glucose utilization: theory, procedure, and normal values in the conscious and anesthetized albino rat. J Neurochem 28: 897--916

24. Baron AD, Laakso M, Brechtel G, Hoit B, Watt C, Edelman SV (1990) Reduced postprandial skeletal muscle blood flow contributes to glucose intolerance in human obesity. J Clin Endocrinol Metab 70: 1525--1533

25. Natali A, Buzzigoli G, Taddei S et al. (1990) Effects of insulin on hemodynamics and metabolism in human forearm. Diabetes 39: 490--500

26. Utriainen T, Malmström R, Mäkimattila S, Yki-Järvinen H (1995) Methodological aspects, dose-response characteristics and causes of interindividual variation in insulin stimulation of limb blood flow in normal subjects. Diabetologia 38: $555--564$

27. Chen YL, Messina EJ (1996) Dilation of isolated skeletal muscle arterioles by insulin is endothelium dependent and nitric oxide mediated. Am J Physiol 270:H2120--H2124

28. McKay MK, Hester RL (1996) Role of nitric oxide, adenosine, and ATP-sensitive potassium channels in insulin-induced vasodilation. Hypertension 28: 202--208

29. Heygate KM, Bennett MA, Watt PAC, McNally PG (1993) The effect of glucose concentration on the endothelium-dependent relaxation in resistance vessels. Diabet Med 10 [Suppl 1]:80

30. Taylor PD, Poston L (1994) The effect of hyperglycemia on function of rat isolated mesenteric resistance artery. Br J Pharmacol 113: 801--808

31. Bohlen HG, Lash JM (1993) Topical hyperglycemia rapidly suppresses EDRF-mediated vasodilation of normal rat arterioles. Am J Physiol 265:H219--H225

32. Mayhan WG, Patel KP (1995) Acute effects of glucose on reactivity of cerebral microcirculation: role of activation of protein kinase C. Am J Physiol 269:H1297--H1302

33. Akbari C, Saouaf R, Barnhill D, Newmann P, Logerfo F (1997) Endothelium-dependent vasodilatation is impaired during acute hyperglycemia. Diabetes 46 [Suppl 1]:114A (Abstract)

34. Baldwin DL, Ohlsen KA, Miller JM, Nuttall AL (1992) Cochlear blood flow and microvascular resistance changes in response to hypertonic glycerol, urea, and mannitol infusions. Ann Otol Rhinol Laryn 101: 168--175

35. Gordon EL, Nguyen TS, Ngai AC, Winn HR (1995) Differential effects of alcohols on intracerebral arterioles. Ethanol alone causes vasoconstriction. J Cerebr Blood F Met 15: 532--538

36. Brown ML, Jakubowski JA, Leventis LL, Deykin D (1988) Elevated glucose alters eicosanoid release from porcine aortic endothelial cells. J Clin Invest 82: 2136--2141

37. Tesfamariam B, Brown ML, Deykin D, Cohen RA (1990) Elevated glucose promotes generation of endothelium-derived vasoconstrictor prostanoids in rabbit aorta. J Clin Invest 85: 929--932

38. Yamauchi T, Ohnaka K, Tanayanagi R, Umeda F, Nawata H (1990) Enhanced secretion of endothelin-1 by elevated glucose levels from cultured bovine aortic endothelial cells. FEBS Lett 267: 16--18

39. Lee TS, Saltsman A, Ohashi H, King GL (1989) Activation of protein kinase $\mathrm{C}$ by elevation of glucose concentration: proposal for a mechanism in the development of diabetic vascular complications. Proc Nat Acad Sci 86: 5141--5145

40. Tesfamariam B, Brown ML, Cohen RA (1991) Elevated glucose impairs endothelium-dependent relaxation by activating protein kinase C. J Clin Invest 87: 1643--1648

41. Inoguchi T, Xia P, Hunisaki M, Higashi S, Feener EP, King GL (1994) Insulin's effect on protein kinase C and diacyl- 
C. Renaudin et al.: Glucose, insulin and skeletal muscle microcirculation

glycerol induced by diabetes and glucose in vascular tissues. Am J Physiol 267:E369--E379

42. Demirci C, Van Lambalgen AA, Stehouwer CDA, Van Den Bos GC (1995) Hyperglycemia per se does not affect microvascular reactivity in rat spinotrapezius muscle. Eur J Physiol 430 [Suppl 4]:R59 (Abstract)

43. Young JB, Rowe JW, Pallotta JA, Sparrow, Landsberg L (1980) Enhanced plasma norepinephrine response to upright posture and oral glucose administration in elderly human subjects. Metabolism 29: 532--539

44. Levin BE (1991) Glucose increases rat plasma norepinephrine levels by direct action on the brain. Am J Physiol 261:R1351--R1357

45. Intaglietta M (1981) Vasomotor activity, time dependent fluid exchange and tissue pressure. Microvasc Res 21: 153--164

46. Intaglietta M (1990) Vasomotion and flowmotion: physiological mechanisms and clinical evidence. Vasc Med Rev 1: 101--112

47. Colantuoni A, Bertuglia S, Intaglietta M (1994) Microvascular vasomotion: origin of laser Doppler fluxmotion. Int $\mathrm{J}$ Microcir 14: 151--158

48. Ragan DMS, Schmidt EE, MacDonald IC, Groom AC (1987) Spontaneous cyclic contractions of the capillary wall in vivo, impeding red cell flow: a quantitative analysis. Microvasc Res 36: 13--30

49. Gustafsson H (1993) Vasomotion and underlying mechanisms in small arteries. An in vitro study of rat blood vessels. Acta Physiol Scand [Suppl] 614: 1--36

50. Achakri H, Stergiopulos N, Hoogerwerf N, Hayoz D, Brunner HR, Meister JJ (1995) Intraluminal pressure modulates the magnitude and the frequency of induced vasomotion in rat arteries. J Vasc Res 32: 237--246
51. Coppack SW, Fisher RM, Humphreys SM, Clark ML, Pointon JJ, Frayn KN (1996) Carbohydrate metabolism in insulin resistance: glucose uptake and lactate production by adipose and forearm tissues in vivo before and after a mixed meal. Clin Sci 90: 409--415

52. Johnson P (1991) The myogenic response, in vivo studies. In: Bevan JA, Halpern W, Mulvany MJ (eds) The resistance vasculature. Humana press, Totowa, New Jersey, pp 159--168

53. Michoud E, Renaudin C, Lagarde M, Wiernsperger N (1996) Reactive hyperemia and veno-arteriolar response are impaired in diabetic rats. In: Messmer K, Kübler WM (eds) 6th world congress for microcirculation, Monduzzi Editore, Bologne, pp 983--987

54. Grunwald JE, Riva CE, Brucker AJ, Sinclair SH, Petrig BL (1984) Altered retinal vascular response to $100 \%$ oxygen breathing in diabetes mellitus. Ophthalmology 91: 1447-1452

55. McNally PG, Watt PAC, Rimmer T, Burden AC, Hearnshaw JR, Thurston H (1994) Impaired contraction and endothelium-dependent relaxation in isolated resistance vessels from patients with insulin-dependent diabetes mellitus. Clin Sci 87: 31--36

56. Tooke JE (1995) Microvascular function in human diabetes. A physiological perspective. Diabetes 44: 721--726

57. Benbow SJ, Pryce DW, Noblett K, MacFarlane IA, Friedmann PS, Williams G (1995) Flow motion in peripheral diabetic neuropathy. Clin Sci 88: 191--196

58. Stanberry KB, Shapiro SA, Hill MA, McNitt PM, Meyer MD, Vinik AI (1996) Impaired peripheral vasomotion in diabetes. Diabetes Care 19: 715--721

59. Bouskela E (1988) Effect of metformin on the wing circulation of normal and diabetic bats. Diabete Metab 14: 560-565 